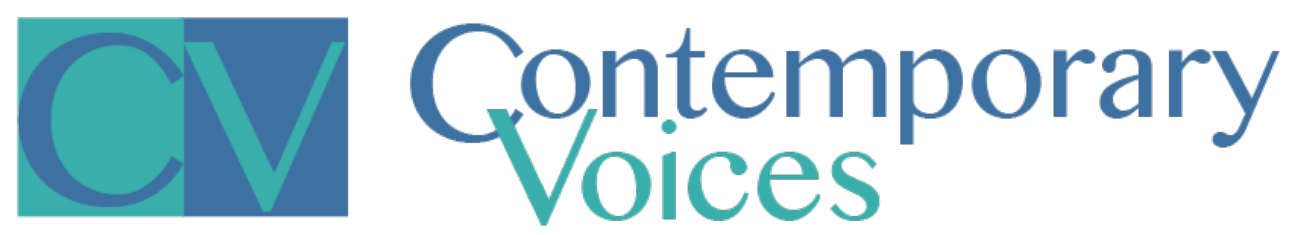

\title{
How do Internet memes speak security?
}

\author{
by Loui Marchant
}

\begin{abstract}
Recently, scholars have worked to widen the scope of security studies to address security silences by considering how visuals speak security and banal acts securitise. Research on Internet memes and their co-constitution with political discourse is also growing. This article seeks to merge this literature by engaging in a visual security analysis of everyday memes. A bricolage-inspired method analyses the security speech of memes as manifestations, behaviours and ideals. The case study of Pepe the Frog highlights how memes are visual 'little security nothings' with power to speak security in complex and polysemic ways which can reify or challenge wider security discourse.
\end{abstract}

Keywords: Memes, Security, Visual, Everyday, Internet.

\section{Introduction}

Security Studies can be broadly defined as analysing "the politics of the pursuit of freedom from threat" (Buzan 2000: 2). In recent decades, scholars have attempted to widen security studies beyond traditional state-centred concerns as "the focus on the state in the production of security creates silences" (Croft 2006: 387). These security silences can be defined as "places where security is produced and is articulated that are important and valid, and yet are not usual in the study of security" (2006: 387). A widening approach seeks to address these silences, allowing for the analysis of environmental, economic and societal threats which are arguably just as relevant to international relations as those emanating from state actors. Visual and everyday security studies are overlapping approaches which seek to break these silences by analysing iterations of security formerly overlooked by security studies.

Internet memes in particular are often both visual and everyday, and as such this article will bring together existing literature by analysing how they speak security. There are many methodological obstacles in the study of internet memes, as they are ever-changing and their sources have questionable reliability. Hence, the nature of the study of internet memes necessitates the use of some unconventional sources. Nonetheless, this analysis remains grounded in academic theory and is essential to understanding how security is spoken today.

The next section of this paper explores the existing literature on visuals, everyday security and internet memes and draws out an essential argument of this paper: that visual memes metaphorically speak both within and outside of their immediate intertextual/intervisual context in ways that text alone cannot. In section two, a bricolage methodological approach draws from the work of many scholars to create a new method of analysis. This method considers meme manifestations as visual objects, as well as addressing the wider visuality of memes through consideration of distribution patterns, humour, polysemy, constitution of truths, affection and displacement of mythical with banal power. Section three responds directly to Andersen et al.'s call for a stronger empirical orientation in visual security studies by applying this new method to the case study of the popular Pepe the Frog meme (2015: 112). This analysis leads to the conclusion that the speech of internet 
memes supports and contributes to, as well as disrupts, dominant security narratives. Memes speak security with ambiguity and polysemy in dramatically contrasting ways depending on their creation, distribution, intertextual/intervisual context and audience. Humour in memes can reaffirm or alter the security claims they are making, sometimes disguising the claim or making it more palatable to certain audiences. Thus, internet memes are not only significant to world politics, but are visual "little security nothings" that are part of a process which allows for the "rupturing" of grand speech acts to securitise.

\section{Security Studies, Visuals and the Everyday}

\section{The Visual}

The visual is arguably "central to the construction of security." (McDonald 2008: 569). In the 21 st century, many scholars have called for the demystification of visuals to aid in understanding and challenging these security constructions (e.g. Der Derain 2005, Croft 2006). Consequently, the last ten years have witnessed the publication of numerous works theorizing visual security. For instance, scholars have analysed televisual media, photographs, colours, symbols and artwork (i.e. Vuori 2010, Hansen 2011 \& 2015, Bleiker \& Butler 2016, Guillaume et al. 2016, Andersen 2017, Vuori \& Saugmann 2018).

This article defines visuals as not only images, videos or visual objects, but also the wider visuality around them. Anderson et al. explain visuality as the process of, 'rendering visible, invisible, or visible in particular ways' (2015: 85). This understanding of the visual also borrows from the work of Barthes, who contends that images, like text, are kinds of speech which can have multiple layers of signified meaning (2000). For instance, a cover of Paris-Match shows a black soldier giving a French salute at one level of meaning, while at a second level it expresses non-discriminatory nature of French imperiality (Barthes 2000: 116).

Barthes argues that "all images are polysemous; they imply, underlying their signifiers, a 'floating chain' of signifieds, the reader able to choose some and ignore others" (1977: 156). In other words, visuals have the "capacity of signs to have multiple meanings" (Andersen et al. 2015: 86). Depending on the knowledge and perspective of the audience, visuals may thus be interpreted in a wide variety of (even contradictory) ways. In this way, polysemy relates to the visual security concept of ambiguity (Möller: 2007, Hansen: 2013). According to Möller, the ambiguity of the visual implies that "no image can be reduced to the meaning assigned to it in a given [verbal/textual] speech-act, politically motivated or otherwise" (2007: 185). In turn, visual security scholarship has since shown how the polysemy/ambiguity of art can create disruptive post-colonial narratives (Bleiker \& Butler 2016), different constitutions of imagery in legal and humanitarian contexts (Aradau \& Hill 2013) and the construction of binaries in racialised and gendered discourses (Aradau \& Hill 2013, Cloud 2006, Schlag \& Heck 2013).

While visuals can be seen as fundamentally polysemic in nature, there remains some contention over how and if visuals and their polysemy 'speak' security. Here 'speaking' means leaving an impression or creating an argument beyond the existing discourse and, in so doing, 'speaking' in a metaphorical sense. Hansen contends that visuals can securitise; although they do not speak alone but rather through their constitution in discourse (2015: 263). This raises the concept of intertextuality, which she defines as the way texts interact with each other, while intervisuality speaks of the same relations between visuals (2011: 53). She then presents an intervisual/intertextual methodological framework for analysing images. In analysing the Muhammad cartoons of the Danish crisis, she presents a four- 


\section{Gontemporary}

point model: 1) the visual itself, 2) its immediate intertext, 3) the wider policy discourse, and 4) the linguistic constructions of the images (2013: 51). For the analysis of 'international icons', meaning widely circulated and recognised images, Hansen introduces a more detailed three-tier framework: 1 ) the image itself, 2) the international status and political impact and 3) appropriations of the icon (2015: 277-8). This second framework recommends the consideration of inter-iconicity, meaning how one icon interacts with others as well as the interpretation of multiple versions of the same image. This focus on only 'iconic' images in the sense of recognisability removes the analysis from the realm of the everyday; however, it raises the question of what makes one image more successful than other versions. One successful image may become 'iconic' in this way because it amalgamates or builds on other images and/or texts to more clearly speak a discourse. Despite arguing that visuals do not speak outside of their context, Hansen does note that they are unique from text alone in terms of their ambiguity, immediacy (in terms of affective response) and circulability (in terms of transgressing linguistic boundaries) (2013: 55-8).

In contrast to Hansen, Schlag \& Heck argue that images have the power to speak metaphorically (2013). They borrow from Bredekamp in contending that this metaphorical speech is a form of auto-activity (2013: 896). However, they also concur, to an extent, with Hansen in acknowledging that images do not exist in a social vacuum but are always embedded in discourses (2013: 907). They employ an iconological approach which takes this social embeddedness into account (2013: 891). In this way, their focus shifts more to the everyday than Hansen's, as they look at 'icons' in the sense of looking at all visuals, as opposed to simply adopting Hansen's definition of icons as particularly memorable and circulated images. However, their analysis mirrors Hansen's in that it expands outwards through 1) describing the pre-iconic subject (defined here as the content of the image prior to symbolic or contextual analysis), 2) undergoing iconographic analysis of the image using knowledge of relevant literary and historical sources, and 3) attempting to determine the meaning of the symbolic form of the image (2013: 899). This article is based on Schlag and Heck's contention that visuals speak metaphorically within and outside of their context, and in different ways than text alone.

Indeed, Andersen et al. demonstrate some of the ways in which visuals speak differently than text and independently of intertextuality in their focus on visuality (2015: 85). The study of colour use is an example of considering how visuality can change how images speak (2015: 91). For instance, Guillaume et al. examine the spatio-temporal significance of the colour change of army uniforms from bold tones to camouflage in terms of the associated evolution of social meanings of battlefields (2016).

Andersen et al. further focus on visuality as speaking security through the constitution of truths, affection and displacement of the mythical with banal power (2015: 94). The constitution of truths refers to how certain ways of seeing strengthen or discredit claims of truth (2015: 97). Der Derain deals with this concept in considering the perceived authenticity of image and film, including the Bin Laden videos (2005: 27-8). While photographs are generally seen as more authentic than other visuals, technical reproducibility brings this authenticity into question (2005: 28). Aradau \& Hill's analysis of the drawings of Sudanese children depicting the Darfur conflict considers how drawings have their validity questioned in a very different manner than other visual objects (2013: 370-2). Secondly, affect as pre-emotion is said to move people through images "in different ways than in the case of words" (Andersen et al. 2015: 100). This relates to Hansen's concept of immediacy. It is particularly true of images that may be tailored to particular "affective intensities and related discourses" (Andersen et al. 2015: 104). Lastly, the notion of banal power borrows from Ranciere's concept of the emancipated spectator (2011). Andersen et al. call for the end of myths about the naivety of the spectator (mythical power), and subsequently for a greater analysis of the role of the 


\section{Contemporary \\ Volces}

audience (banal power) (2015: 112). They state that we should "see what [images] do, and what their viewers do with them" (2015: 112).

\section{The Everyday}

Much of contemporary security studies is built on the foundations of Buzan et al's securitisation framework (1998). According to this framework, a securitising actor makes a speech act identifying an existential threat. This threat is said to endanger a referent object (i.e. a population needing protection) in ways that warrant extraordinary counteractive measures (1998: 21). Securitisation is successful only when it convinces the intended audience (1998: 31). Vuori describes the normative element of securitisation theory as altering "'security' from the inside by unmasking its operative logic and stripping away its innocent appeal" (2017: 66). Through critique of security discourses, International Relations may focus less on political actions justified through security concerns and more on transparent politics (Vuori 2017: 67). This is related to the notion of desecuritisation, or removing issues from the security agenda, by deconstructing their operative logic (McDonald 2008: 566).

However, the 'operative logic' of security arguably cannot be fully 'unmasked' without acknowledging the elements which traditional securitisation theory continues to overlook by maintaining a narrow focus on grand speech acts by political leaders (Williams 2003: 525, McDonald 2008: 569, Huysmans 2011, Schlag \& Heck 2013). This narrow focus dismisses the analytical value of everyday, banal security practices. This concept of banal power in visual security ties in with the IR theory of the everyday, which suggests that the analysis of banal, commonplace events can make important contributions to analysis (Enloe 2011). The mystification of the link between the personal and the political leads to assumptions about who has knowledge (Tickner 2005). In other words, it "designates the practice of IR as the exclusive domain of experts, statesmen, diplomats and...chieftains of global business" (Davies \& Neimann 2002: 561). Everyday IR theorists reject this exclusivity. They call for the disruption of the binaries of "inside/outside, low politics/high politics [and] unremarkable/remarkable" in which the former descriptors are considered unimportant to traditional IR (Guillaume 2011: 459). They contend that relations occurring on 'private' sites reify and legitimise the power relations of 'public' state-level politics (Enloe 2011: 447). For example, Enloe notes that the production efficiency at public-sphere export factories relies on the assertion of traditional gender identities in the private context of soldiers' households (2011: 448-50). Guillaume further argues that when the everyday is included in scholarship, it tends to be associated with a romanticised concept of resistance (2011). He examines the 'myth' of "the quotidian individual... as an inherent locus of resistance to global phenomena of domination and injustice" (2011: 460). In turn, he stresses the need for a wider assessment of everyday sites and tactics.

Huysmans further brings the theory of the everyday to security analysis by exploring security practices, including data collection and CCTV surveillance, which might be considered "little security nothings" when compared to grand, existential speech acts $(2011,2015)$. These traditional acts of securitisation must follow certain linguistic-grammatical rules and the speaker must hold a position of power from which the act can be carried out (Williams 2003: 525). Huysmans critiques this exceptionalism by contending that securitisation is not one existential rupturing speech act, but a process taking place through a myriad of seemingly insignificant critical decisions or 'nothings' (Huysmans 2011: 3). While Vuori notes, "[a]udiences that grant moral support for security policies may differ from those that can grant deontic powers" (2017: 68), Huysmans' framework maintains that the acts and relations of both audiences are the small but significant decisions which make the 'existential' and deontic securitising speech acts of political leaders possible. 
Methmann et al. perhaps come closest to bringing together theoretical perspectives on security, the visual and the everyday (2014). In their analysis, they follow Huysmans' lead by calling visual constructions of Climate Induced Migration (CIM) "visual little security nothings" (2014: 162). CIM is an unknown threat as there is no certainty about potential harms (2014: 164), however the visuals used play into a wider gendered and racialised colonial narrative about the encroachment of 'nomadic' irregular migrants into the Schengen space (2014: 171-3). Their article thus demonstrates the importance of analysing seemingly banal visuals in order to understand how they contribute to security discourse.

Scholars have also developed assessments of the roles of popular culture and humour in everyday security. Weldes \& Rowley argue that popular culture may seem trivial, but it actually reflects the broader cultural resources of society (2012: 514). They explore the performance of in/securities and identities in television through the empirical example of the TV shows Buffy the Vampire Slayer and Angel. These shows both present a realist perspective in earlier seasons, which evolves into a deeper, wider and more identity-focused understanding of security by later seasons (2012: 5245). Meanwhile, those with power can use humour to maintain hierarchies in security discourses (see Harrington 2014). The restriction of humour in certain spaces, i.e. airports, can maintain their construction as hyper-securitised sites in dominant narratives (Salter 2015: 31). On the other hand, humour can be "central to modes of critique and the formation of discourses which seek radical cultural transformation" (Campbell 2011: 159). The ambiguity of jokes can further undermine the presentation of security as an issue of certainty and severity (Salter 2015: 39). This ambiguity can also be used to 'other' certain populations. As Särmä notes, "[l]aughter at certain Others of world politics can violently push them beyond the boundaries of human polity" (2015: 114). Conversely, humour can question this 'othering' and thus de-securitise (Campbell 2011). Ultimately, "laughter is always tied up with power" and can tell us something about power relations in regard to speaking security (Särmä 2015: 113).

\section{Internet Memes}

In recent years, and in parallel with these developments in security studies, scholars from a range of academic fields have developed analytical frameworks to analyse the phenomenon of internet memes. The term 'meme' was first defined by Richard Dawkins in 1976 as the cultural equivalent of a gene which leaps "from brain to brain via a process which, in the broad sense, can be called imitation" (1989: 192). He presents the examples of "tunes, ideas, catch-phrases, clothes fashions [and] ways of making pots or of building arches" (1989: 192). As the term gained in popularity and became more synonymous with developments on the internet, sociological and literary studies of the phenomenon began (Knobel \& Lankshear 2007, Davidson 2012, Shifman 2014). These sought to bridge "the yawning gap between (sceptic) academics and (enthusiastic) popular discourse about memes" (Shifman 2014: 4).

In his work on providing a descriptive vocabulary for classifying internet memes, Davidson defines them as "a piece of culture, typically a joke, which gains influence through online transmission" (2012: 122). He notes how memes have three key components: the manifestation (as sets of objects, e.g. cat pictures), the behaviour (actions taken by individuals, e.g. taking and editing photographs of cats) and the ideal (the idea of the meme, e.g. that cats are funny) (2012: 123). While Davidson agrees with Dawkins' original notion of the replication and mutation of memes, he argues that these are subjective and intentional acts (2012: 123). Dawkins has since agreed that the mutation of memes online does not happen through random change, but creative human alteration (Solon 2013). 


\section{Gontemporary}

Alternatively, Shifman defines an internet meme as "a group of digital items sharing common characteristics of content, form, and/or stance; (b) that were created with awareness of each other; and (c) were circulated, imitated, and/or transformed via the Internet by many users" (2014: 7). This definition shares with Davidson's an acknowledgement of the role of meme mutation. Shifman also stresses the intertextuality of memes as they often relate to others in diverse ways (2014: 2). She perceives a single cultural unit (video, photo etc) to be a viral while an internet meme is always a plurality or collection of such cultural units (2014: 56). Arguably, this notion of the viral equates to a single manifestation in Davidson's framework. This article borrows from both scholars in its definition of internet memes as deeply intertextual/intervisual groups of cultural units shared online and made up of manifestations, behaviours (of creation, circulation, imitation and mutation) and ideals. In sum, individual cultural units such as photos represent one manifestation of a wider meme.

Knobel \& Lankshear further develop Dawkins' original criteria for a successful meme: longevity, fecundity and copying-fidelity (Dawkins 1989: 194). They define fidelity as the qualities of a meme that make it easy to distribute, fecundity as the rate at which the meme spreads and longevity as the length of time a meme stays in transmission (Knobel \& Lankshear 2007: 201-2). They further suggest the additional criterion of susceptibility as "the 'timing' or 'location' of a meme with respect to people's openness," to it (2007: 202).

As such, internet memes fall on the intersection of the visual and the everyday. Memes are often images, or combinations of image and text, and thus are often visual (Davidson 2012: 127, Särmä 2014: 67), while they are also everyday in terms of how they are created and distributed. Anyone with internet access can make, view, share and edit memes. This occurs in what might be termed the 'private sphere' of 'non-expert' geographical, cultural, social and political online communities. Interestingly, in recent years, media outlets and international figures have referenced the importance of internet memes in global politics (e.g. Clinton, in Revesz 2016). Despite this, academics in the IR field are only just beginning to theorise the meme phenomenon (Hamilton 2014, Hristova, 2014, Särmä 2014, Nagle 2017).

IR meme scholarship has largely built upon an increasing body of work on the political significance of the Internet. Shirky writes on how recent US Internet freedom policy has 'overestimated' broadcast media and 'underestimated' private communication on social media in fostering political change (2011). In her analysis of Internet culture wars, Nagle references a number of memes used by both the political left and right to assert their collective political identities and to mock their political opponents (2017). Warrington in turn considers how civil society actors have the ability to present de-securitising narratives on Twitter (2017). In addition, Andersen addresses the significance of digital videos (a form of meme) in mediating security articulations in a very different manner from traditional visual media (Andersen 2017). The public actively constitutes the virality of such videos, as viewing such data brings them to the attention of mass media (2017: 362).

Some scholars have noted that many memes directly address issues related to IR scholarship (Hamilton 2014, Särmä 2014, Hristova 2014, Mina 2014). Hamilton concludes:

Audiences that engage with international affairs via internet memes are almost certainly larger in number and demographic variety than those that read our books and journal articles...these are the images that contribute to the worldviews of our 'digital native' students' (2014).

Subsequently, these are the images that make up the myriad of 'little nothing' security articulations produced by these audiences. 
These pioneering assessments of the role of internet memes in IR highlight that while memes are often everyday, they are by no means irrelevant to politics. As such, they are a phenomenon warranting further investigation. While meme studies, visual security and everyday security are all flourishing research areas, they have not yet been merged, as a visual security analysis of memes recognising the importance of the everyday is currently missing from the IR literature. This article seeks to fill this research gap by examining how memes speak security. In so doing, it responds to calls to increase visual security and everyday security analysis, as well as deepening our theoretical understanding of internet memes. As Ranciere notes, '[p]olitics revolves around what is seen and what can be said about it, around who has the ability to see and the talent to speak' (2004: 13). An understanding of how internet memes speak security will illuminate how this phenomenon might be changing what it means to have political visibility: the ability to see and talent to speak. The next section will draw from this literature review to present a new methodological framework for the empirical study of internet memes as everyday visual speakers of security.

\section{A Methodology of Memes}

This section draws from the scholarly work explored in the previous section to create a new methodology to study internet memes as visual speakers of security. This analysis is guided by a reflexive epistemology, which maintains that the interpretation of memes is highly subjective and subsequently acknowledges the subjectivity and positionality of the author. This methodology is built around a theoretical understanding that brings the visual and everyday into the realm of security studies in a way that can teach the IR scholar a great deal about how security is constituted. Thus, first and foremost, it takes the intersection of the visual and the everyday seriously, grounding itself in a relational ontological understanding that "images [and subsequently memes] are as much the producers of their reality as they are its products." (Schlag \& Heck 2013: 897). While there are many non-visual internet memes, this article focuses on visual memes in order to understand how they speak security in multiple and complex ways.

There are a number of notable methodological challenges in this study. The first is that online culture is fast-paced and ever-changing as "stuff circulates at an incredible speed from one corner of the world to another" (Särmä 2015: 111). As Bleiker notes, "website headlines often change by the hour or even minute," making it harder to identify visual patterns in the static manner one would analyse a newspaper (2015: 877). Internet memes are thus replicated and mutated incredibly quickly across multiple online platforms. In turn, many are created anonymously and may have originated on private forums or semi-private social network sites. Details of their creation and mutation may also be reported by unreliable sources. All of this makes their intent, lifespan and impact harder to analyse.

These memes are visual objects or manifestations, but they are also the behaviours and ideals which bring about these visual objects (Davidson 2012: 123). The methodology presented here aims to take these obstacles into account. In order to address the overall complexity of the internet meme phenomenon, it will draw from a variety of methods in its analysis. Andersen et al. highlight that the visual is so diverse that it would be too limited by a single research programme (2015: 87). Bleiker furthers this idea by calling for pluralist methods in visual global politics research (2015). This article thus engages with Aradau et al's notion of methodological bricolage as a way of experimenting with methods, not to seek certain knowledge, but to rather "bring out relations that otherwise remain largely invisible" (2015: 7).

Drawing primarily from Schlag \& Heck (2013), this article acknowledges that memes speak both within and independently of their intervisual/intertextual context. They are best understood through 
employment of a methodology which considers both their context and the visual qualities of their speech that cannot be replicated in words. Thus, this methodology centres on an intervisual/ intertextual method for analysing visual objects. This borrows from Vuori, Schlag \& Heck and, most notably, Hansen. However, it also considers the wider questions of meme visuality explored in the literature review, including distribution practises, humour, constitution of truths, affection and displacement of mythical with banal power. This framework will allow for the acknowledgement that memes speak in a plurality of ways to audiences across varying geographic and temporal contexts.

This original method is broadly sequential in that it suggests an order for analysis that moves from a focus on the pre-iconic manifestation of a meme to a wider assessment of its position in discourse. The method will not apply to all manifestations in the same way and will likely apply differently to one manifestation over time. It will be most relevant to those memes with political ideals (e.g. not to those whose ideal is solely that cats are funny).

This method is further supported by a number of methodological assumptions. Firstly, internet memes are constantly referencing other memes, from both online and offline, in their creation and mutation. This forms Barthesian-style chains of signification which can alter interpretation of the meme as a visual object. Secondly, it is assumed that the audiences of memes have banal power in that they are empowered to actively participate in the process of creating, interpreting, sharing and altering memes (Shirky 2012: 239, Solon 2013). This participation empowers individuals as pop culture producers, due to the fact that virtually anybody can create memes with potentially global reach (Särmä 2014: 67). These producers are often not powerful individuals; indeed, they are often anonymous. They may not have the perceived authority to make a securitising speech act within the framework of traditional securitisation theory, yet the memes they create in banal settings are 'little security nothings' which together make up Huysmans' formulation of the securitising process. Thirdly, this approach maintains that the way memes are created and mutated likely contributes to them being constituted differently than other forms of visual objects. This is due to the fact that memes are not necessarily seen as truths, but as opinions or jokes (Davidson 2012: 122). Thus, the constitution of truthfulness will also vary greatly from meme to meme. Much like Der Derain's take on photography, memes which use photographic visuals may be seen in a different light than cartoon memes (2005: 28).

As internet memes are often seen and even defined as jokes, this methodology acknowledges that memes can and often do speak using the communicative tools of humour and irony. Subsequently, humour can change the meaning and reception of the meme amongst certain audiences. The humour used is often exclusive, inviting only certain viewers with certain types of knowledge to join in with the laughter (Särmä 2015: 114) On the one hand, it can be used to strengthen a meme's support for existing power structures, which Särmä dubs 'hegemonic laughter' (Särmä 2015: 114). However, humour can also be used to strengthen memetic disruption of the dominant narrative. It also can be used to 'other' certain populations (Särmä 2015) or to question this 'othering' and thus de-securitise (Campbell 2011).

The role of humour ties in with perhaps the most important methodological assumption of this article; namely that memes, like all visuals, speak with a deep polysemy and ambiguity. The frequent anonymity of memes' creators and mutators often makes the intent behind them unclear and open to debate. Even when intent is expressed, audiences still interpret the same meme in a variety of ways. References to other memes and specific forms of knowledge contribute to these different interpretations. Humour means that it is not clear when to take the security speech of a meme 'seriously'. As author of this article is not likely to have the knowledge to appreciate the full 

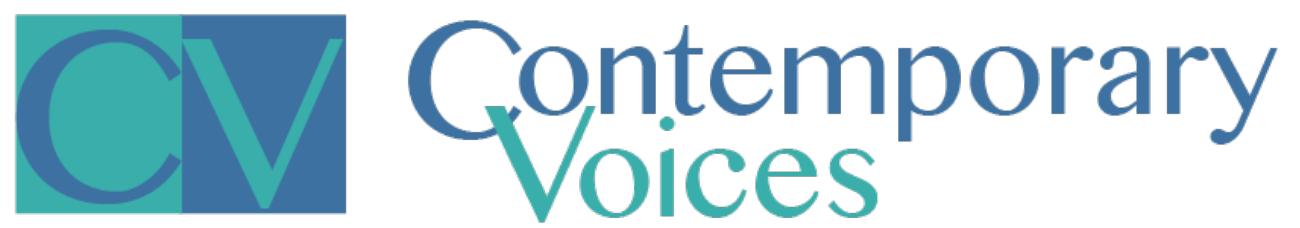

polysemy of every meme, it is not able to definitively confirm the intent of a meme creator, nor the interpretation of every audience.

Bearing these methodological assumptions in mind, this article draws together scholarship on memes, visuals, visuality and banality to present this five-point sequential method for determining how memes speak security:

1. The pre-iconic meme

- What do we see by looking at this manifestation's visual content before we have applied symbolic and contextual analysis?

2. Immediate intertextual/intervisual analysis

- How do visuals and text (if applicable) within the meme interact with each other?

- Is there immediate intertext and how does it interact with the manifestation?

- Where was this manifestation found online and does this alter its speech?

- Does the manifestation have a named author? What is the impact of this?

- Are there recognisable characters/scenes within the manifestation? What inter-iconicity is evident?

3. The wider policy discourse

- What is the political context? Is there susceptibility?

- What is being said about the topic of the meme?

4. Constitutions of the manifestation

- What are people saying about the manifestation?

- Is it being constituted as truthful? In what ways?

- Do any aesthetic elements of the meme shape interpretation?

- In what ways is the manifestation polysemic/ambiguous?

- Has it elicited a strong affective response?

- Is the manifestation being perceived as humorous? How does this impact response?

- What can be said about the manifestation's longevity and fecundity?

- What behaviours and ideals are being encouraged by this manifestation?

5. Appropriations of the manifestation

- Does the manifestation have strong copying-fidelity?

- Is this manifestation an appropriation of another?

- Are there notable appropriations of this manifestation? If so, how do they support/subvert the manifestation's original message?

In sum, this method is designed to focus on memes first as manifestations, then as behaviours and ideals. This begins with a basic description of the content of the manifestation, before considering its symbolic and referential elements. It then contextualising it within broader security narratives and debates. An exploration of wider visuality also acknowledges how these memes speak in ways text alone cannot; mainly through aesthetics, humour and affect. In turn, while analysis of susceptibility, longevity, fecundity, copying-fidelity and other habits of audience engagement focus on the behaviour/s of the meme, the consideration of the polysemy and perceived truthfulness of the meme allows for a clearer understanding of its ideal/s. While this method may never fully capture all of a meme's iterations and intricacies of speech, these layers of analysis allow for a clearer understanding of how memes speak security in different times and spaces as well as what they say to different audiences. 


\section{Gontemporary}

\section{Little Amphibian Nothings: The Case Study of Pepe the Frog}

Pepe the Frog is an 'anthropomorphic frog character' created in 2005 by comic book artist Matt Furie (Know Your Meme (KYM) 2018a). Pepe was one of four main characters in Furie's comic series Boy's Club. The comics' plotlines were generally light-hearted, revolving around the "blissfully stoned frog" and his friends leading a "simple life" of eating, drinking, gaming and crude humour (Furie 2016). In 2008, a toilet humour joke from the comic in which Pepe says, "Feels good man" was posted and popularised on the 4chan /b/ (random) messaging board (KYM 2018a). This board is one of the most well-known on the 4chan site, as it is not limited to any specific type of content and there are minimal rules policing what can and cannot be posted (KYM 2018b). Users of /b/ board are generally internet-savvy and less 'politically correct' than the average person in that they oppose limitations on their freedom of speech and praise memes with 'shock value' (KYM 2018b).

Over the next few years, the Pepe meme grew in prominence online. The 'Feels good man' smiling Pepe (image 1) ) $^{[1]}$ was one of a number of manifestations of the meme which became templates for further mutations. I shall refer to these templates as 'Reaction Pepes'. Other notable Reaction Pepes include the 'Feels bad man' sad Pepe and smug Pepe (images 2 and 3 ). In a very short time, users of the meme had a Reaction Pepe at their disposal for almost every form of broad emotional response, which could then be tailored to create manifestations fitting specific situations. Pepe had become "a symbol fit for all of life's ups and downs and the full spectrum of human emotions, as they played out online" (Nuzzi 2016).

By 2014, Pepe was a widely recognised meme character across the internet. He had his own Tumblr and Facebook page (KYMa), and high-profile celebrities were posting humorous images of the frog on their social media (KYMa). 'Rare Pepes', meaning particularly unusual images of the frog were being swapped, bought and sold online as if they were collectables (KYMa). Pepe was constantly being reified as a meme: a series of manifestations, a set of behaviours and an attached set of ideals. The manifestations were the many Reaction Pepes, Rare Pepes and other Pepe images posted online. The behaviour was the making, sharing, liking and altering of these images across the internet. The associated ideal was generally a belief that Pepe was a funny and relatable character. This ideal is seemingly what gave the frog such mass appeal.

However, the Pepe meme was already speaking in political and polysemic ways at this early life stage. Even the most seemingly banal and non-political Pepe meme was edited, framed and distributed in selected ways. Theory of the everyday highlights that these decisions may seem insignificant but were in fact political decision-making happening on a small scale. Moreover, "at the end of the day, he [Pepe] meant whatever you wanted him to mean" (Nuzzi 2016). The wide appeal of the character meant he was used in memes to express opinions from across the political spectrum in both overt and subtle ways. Pepe's association with humour meant that these memes often spoke security to audiences with humour and irony, but they also spoke with even deeper ambiguity. Layers of irony could strengthen the voice and message of a meme to certain audiences, while mystifying or softening its speech to others. As the meme grew in popularity, there appears to have been something of a backlash on sites including 4chan $/ \mathrm{b} /$, where the meme became popularised. By 2015, Pepe was the biggest meme on Tumblr (Nuzzi 2016). However, the character was having something of a memetic identity crisis; speaking security with such increasingly contrasting political agendas in increasingly complex and subversive ways.

This article will now apply its original five-point method to four manifestations of the Pepe meme. The method will be followed in a broadly chronological manner, although adapted slightly to fit each manifestation. These manifestations have been selected using Särmä's method of 'reverse- 
snowballing' (2015: 117) The images were found through internet browsing, following links, reading thought pieces on the meme and referring to biographies of the Pepe character in meme encyclopaedias such as KYM. The 'reverse-snowballing' process was selected so that empirical data could be found in a manner mirroring the slightly random and ever-shifting nature of online memetic encounters. From this data, the Pepe manifestations selected for analysis have spoken security in loud and contentious ways, and in so doing have helped to shape or alter the behaviours and ideals of the meme. These manifestations are analysed in a broadly linear order from the date first shared online. While it is never certain when a manifestation was first posted, this consideration of rough temporal order helps to foster an understanding of how the security speech of this meme has evolved.

Throughout the analysis, it is worth noting two things. Firstly, the manifestations selected here are merely a snapshot of thousands of manifestations of this meme which have each acted as seemingly small but significant developments in building and altering how Pepe speaks security. Secondly, each of these selected manifestations are more than the single visual objects displayed, but simultaneously have a much wider visuality, which will subsequently be explored.

\section{Manifestation 1}

The first manifestation of the Pepe meme this article will analyse is the 'Super Rare Skinhead Pepe' (Premium Pepes 2018) (Image 4). In pre-iconic terms, this image shows the face of a smiling green cartoon frog, recognisable as Pepe, with multiple words and pictures drawn on his face and neck in black ink. The image was found on a Tumblr page called "PremiumPepes," which also displays many other Pepe images. The implication here is that the page owner is very familiar with the Pepe character. This particular manifestation was posted in April 2015 at the request of another Tumblr user called Kuailfy, whose own Tumblr board displays a great deal of violent, sexual and right-wing imagery (2018). In terms of immediate intertext, the title assigned to the image references the humorous 'Rare Pepe' meme, although it is unclear if it does so ironically. It also suggests that this Pepe is in the likeness of a 'skinhead', a term which stereotypically refers to a white male with a shaved head who is prone to violence and/or white supremacist beliefs. In terms of fecundity and longevity, this manifestation appears to have been only moderately shared, at least across public internet sites.

However, this image does tap into the fecundity and longevity of the wider Pepe meme, and through inter-iconicity it speaks security with and alongside a number of other manifestations. The symbols on Pepe's skin, in addition to the skinhead reference, suggest a very specific and aggressive articulation of security. Under each of Pepe's eyes is a swastika, a symbol that is today almost universally associated with fascism. The number 14 on the left eyelid is numeric shorthand for "we must secure the existence of our people and a future for our children', while 88 on the right eyelid can mean 'Heil Hitler' (Nuzzi 2016). The number 5150 may refer to the California police code for taking a dangerous mentally ill suspect into custody (California WIC 2018). Other symbols on Pepe's face appear to include the Valknot and Celtic Cross, which are both associated with white supremacy (ADL 2018c\&d). Some of these symbols have multiple meanings, including non-white supremacist associations. However, their inclusion together in this image means most audiences are likely to interpret this manifestation as speaking security in a way that presents white people as the referent object and other races as threats.

It is arguably because of the overtly white supremacist speech of this manifestation that it has not been more susceptible to virality. In wider political discourse, international organisations and state governments are generally opposed to overt expression of white supremacist ideals. However, 


\section{Gontemporary}

Nagle highlights how the Internet culture war of the 2010s has given the 'Alt-Right' the space to form as a political movement in favour of free speech and against liberal 'political correctness' (2017: 11). Within certain Internet communities, 'Alt-Right' ideas, which range from traditional conservatism to fascism, have become recognised as normal and celebrated. Forums like 4chan, and the memes created and shared in these spaces, have given this new Alt-Right movement a 'youthful energy' (Nagle 2017: 13). Amongst the alt-right, and indeed among others who reject that label, references to white supremacy were growing more permissible and amusing at the time this image was shared.

In terms of how this meme has been constituted, traditional media sources have generally overlooked manifestations such as this as unimportant speakers of security. This lack of serious attention is perhaps due to the deeply affective symbolic content of the image being juxtaposed by the cheerful aesthetic of a cartoon frog and the setting of a moderately popular Tumblr page. However, some retrospective analysis has been attempted. Nuzzi appears to reference this particular manifestation in a 2016 Daily Beast article which makes the argument that Pepe has become a white supremacist symbol. She contends that this version of Pepe is evidence of the grim versatility of the meme and its use as an alt-right weapon (2016). She quotes alt-right Twitter users who claim that the association of Pepe with the Alt-Right has been built intentionally as a backlash against "normies," meaning mainstream Internet users (2016). Some right-wing publications have since mocked Nuzzi's conclusion. The Daily Caller, for example, declared that Nuzzi had been 'trolled' by such images and her interviewees (Bennett 2016). The suggestion here is that manifestations such as this are purely humorous vehicles for the mockery of those, like Nuzzi, gullible enough to critique them. As Nagle notes, "interpretation and judgement are evaded through tricks and layers of meta-textual self-awareness and irony" (2017: 31). While the white supremacist speech of this manifestation is therefore relatively unambiguous, the polysemy of this image is still disputed as some audiences claim to perceive Pepe as speaking 'white' security in jest.

Although there is still a degree of ambiguity in the ideal of this meme, it is arguably encouraging a behaviour of associating the Pepe character with white supremacist insignia in online imagery. In terms of copying-fidelity, this behaviour proved easy and popular to replicate. This is evidenced by other mutations of the Pepe meme which use some of the same symbolic references and were becoming increasingly popular at the time this image was posted. It is not clear which precise manifestation/s began this trend, but perhaps more important is the fact that manifestations continued to build from and blend into each other to create the association. This particular manifestation is part of a chain of memetic signification which has shaped how the overarching Pepe meme has spoken to various audiences since, particularly as a white referent object.

\section{Manifestation 2}

This manifestation depicts a blond-haired Pepe holding up a badge that says "Trump" and, "Make America Great Again" (Image 5). On the other side of a fence labelled "US Border," stand a man and a woman holding a baby. This couple are wearing stereotypically Mexican clothing. The man's expression appears angry, while the woman's is perhaps best understood as submissive and sad. This manifestation was posted by the Malaysian artist Maldraw onto 4chan's /pol/ (politically incorrect) board in July 2015 (KYM). As a result, early viewers will more likely have been a part of the alt-right movement. An intertextual/intervisual analysis suggests this image shows a Smug Pepe representing a satisfied Donald Trump. The two Mexican characters are drawn with the face of another common meme; Wojak or 'the Feels Guy'. Since the early 2010s, Wojak has typically been used as a reaction image to express feelings including regret, melancholy and loneliness (KYMd). 

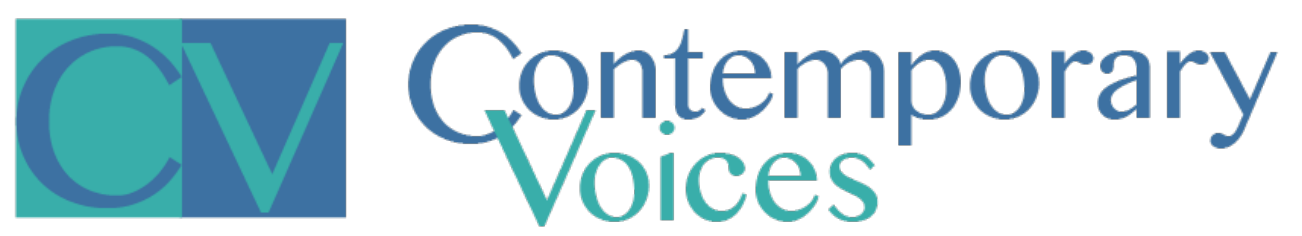

The character is also included in many 'I know that feel bro' memes expressing genuine or mock empathy. Wojak and Pepe have a long relationship history in meme culture (KYMd). While some manifestations depict the characters as friends, there has been a trend since 2014 of depicting them as nemeses. Comic series and manifestations have shown Pepe committing "various unethical acts towards Wojak" (KYMd). A binary has emerged; framing Pepe as strong, funny and masculine, and Wojak as emotional, weak, feminine and other. Arguably, this manifestation is playing on assumed knowledge of this binary.

This manifestation has proved very popular in terms of longevity and fecundity and can now be found on multiple social media and search engine platforms. This is perhaps due to the susceptibility of how well its speech was attuned to popular contemporary security narratives. At the time this manifestation was first shared, then presidential candidate Trump was presenting a contentious security narrative about the Mexican border. In a series of comments, Trump clearly marked out Mexican immigrants as an existential threat to the referent object of US citizens. For example, he tweeted a month before the creation of this manifestation that, "Mexico is not our friend. They're killing us at the border and they're killing us on jobs and trade" (Reilly 2016). Trump made a campaign promise that a wall would be built between Mexico and the USA. An example of his framing the wall as the extraordinary action needed to counter the existential threat of immigration is his March 2015 tweet stating, "I want nothing to do with Mexico other than to build an impenetrable WALL and stop them from ripping off U.S." (sic) (Reilly 2016). Given the timing and intertextuality/intervisuality of this manifestation, it can be assumed that the fence in the image represents this promised wall.

This manifestation can thus be seen as reiterating and building on Trump's securitisation of the USMexico border. Its popularity suggests that it was being constituted as telling a truth by many within and beyond the 4chan community. The manifestation remains polysemic/ambiguous in so far as it can still be framed as a 'joke'. This 'joke' is arguably employing hegemonic laughter to mock and 'other' those represented by the Wojaks. The manifestation is thus affective in that it likely either incites laughter at the 'other' or anger and rejection of that laughter. This anger might be interpreted as not 'getting' the joke. Another layer of ambiguity here is whether 'Trump Pepe' shares the same beliefs as 'Skinhead Pepe' and other alt-right iterations of the character. This manifestation is a key stage in building the association between Trump and the alt-right precisely because of the visual stickiness of Pepe signifying alt-right beliefs in other manifestations. While not all audiences picked up on or agreed with this stickiness, this manifestation appears to have contributed to a memetic ideal of Trump as an Alt-Right hero as well as a behaviour of using Pepe to put this message across in a comical, and thus more ambiguous, way.

This is evident in the vast number of appropriations of this manifestation, which had very high copying-fidelity. It is particularly interesting to note that in many appropriations, the Wojak Mexicans had their colourless skin coloured in brown (Wordpress 2018). In line with Aradau \& Hill, this can be seen to racialise the security speech of the Pepe meme. In a further series of appropriations, the core layout of the image was altered slightly to depict Pepe as other political leaders, particularly those revered by the Alt-Right, or simply as a caricature of a particular nation, while the Wojaks would be altered to represent the non-white, non-European 'other' deemed to be the existential threat.

\section{Manifestation 3}

In September 2016, Trump's son, Donald Jr, posted a Pepe manifestation on Instagram (Image 6). The image features Pepe, Trump, Trump Jr and other Republican and alt-right figures, including Mike Pence, Ben Carson, conspiracy theorist Alex Jones and former Breitbart writer Milo Yiannopoulus. 


\section{Gontemporary \\ olces}

Each of their faces have been edited onto the bodies of men in combat gear. The words 'The Deplorables' are superimposed over the image. Trump Jr was not the only individual in the public eye to share this particular manifestation. Trump advisor Roger Stone had shared the same image previously and has been credited with the creation of the manifestation (Owen 2016). Trump Jr's post brought the image further into the public eye. With over 11000 Instagram likes, it increased the overall fecundity and longevity of the manifestation. An excerpt from Trump Jr's post caption reads, "All kidding aside I am honoured to be grouped with the hard-working men and women of this great nation that have supported @realdonaldtrump...He's fighting for you and won't ever quit" (Trump Jr 2017).

Intervisual analysis reveals that this is an edited version of the film poster for The Expendables. The 2010 film launched a series which brought together an all-male group of actors famed for playing action heroes. In the first film, they act as a group of mercenaries with the mission to "eliminate a Latin dictator and renegade CIA agent" (IMDb 2010). These men carry out dangerous, violent and secretive missions; "the type...the US government wouldn't be able to officially sanction" (Owen 2016). The textual pun in the meme stems from a comment made by Hillary Clinton at a private fundraiser where she stated that half of Trump's supporters belonged to "a basket of deplorables" (Jacobs 2016). Thus, those who Clinton perceives as deplorable become the Expendables here. This parallel relies on popular culture to portray Trump and allies as a highly masculinised and militarised team of patriotic yet rebellious Americans. They offer patriarchal national protection from existential threats. Interestingly, the films include both internal threats and threats from states close to the US border.

Mere months before the Presidential election, this manifestation was shared at a crucially susceptible time in the security narratives of both the Clinton and Trump campaigns. In her 'deplorables' speech, Clinton had called some Trump supporters "racist, sexist, homophobic, xenophobic, Islamophobic," and, "irredeemable" (Jacobs 2016). She would soon ask voters to imagine the threat of Trump having access to US nuclear codes (NBC News 2016). She and her team were constructing a narrative of Trump as a security threat to the referent object of minority groups, the wider nation and even the world. On the other hand, Trump was tweeting and speaking regularly of 'Crooked Hillary' (Trump 2016), and in a month's time he would make his first call for Clinton to be 'locked up' (The Guardian 2016). Shortly afterwards he would first use the language of 'draining the swamp' in Washington, meaning to eliminate establishment bureaucrats (Harrington 2016). This manifestation thus speaks security in line with Trump's narrative of an administration which would protect the American referent object, using extraordinary measures if necessary, from both external forces like immigrants and internal establishment forces like 'Crooked Hillary'.

The inclusion of Pepe in this manifestation continued the trend of associating Trump with the cartoon frog. The popularity of this trend had been buoyed a year earlier when Donald Trump himself had retweeted a manifestation of the Trump-Pepe hybrid meme (Trump 2015). However, wider Pepe discourse was also continuing to associate the character with white supremacist ideals. Before his turn as Trump, Pepe had been portrayed as many seemingly apolitical, funny and innocuous characters. However, there was now a clear pattern of Pepe's depiction as a white supremacist and as anti-Semitic characters, including the aforementioned skinhead, KKK members and Adolf Hitler. The behaviour of associating Trump with alt-right ideals continued to escalate in appropriations and mutations of the Pepe meme from this point until the Presidential election (KYMe). Thus, the inclusion of Pepe in this manifestation might also suggest a racialised quality to the protection offered by the Trump administration. 


\section{Gontemporary \\ Volces}

In term of constitutions of this manifestation, Hillary Clinton's team posted a Pepe meme exposé on their campaign team website mere days after Trump Jr's Instagram post. Clinton's team emphasised the link between Pepe and white supremacy and called it "horrifying" (Revesz 2016). The article specifically referenced the Deplorables image as one linking the Trump campaign to white nationalism. The piece was met with some ridicule, but "after the laughter died, the media continued to label Pepe as an alt-right icon" (Di Placido 2017). Trump Jr claimed ignorance of the association between Pepe and white supremacy, as he told Good Morning America that he had never seen the meme before, and that he "thought it was a frog in a wig...I thought it was funny" (Nelson 2016). This comment coupled with his Instagram caption act as signposts for interpreting the meme in a humorous way. Nonetheless, there is still ambiguity over how this manifestation is to be interpreted. Certain audiences will find the meme funny, but likely for different reasons. Depending on their knowledge and interpretation of the meme they may have an affective response which causes offense, confusion or a sense of belonging.

Interestingly, a matter of weeks after this manifestation was posted, the Anti-Defamation League (ADL) contested the security narrative of the Pepe character by constituting the meme as a potential security threat. The organisation made the decision to classify Pepe the Frog as an alt-right hate symbol, on the basis that the meme was repeatedly appearing in anti-Semitic and racist contexts (Kircher 2016). This seemingly eliminated some of the ambiguity around the Pepe character. However, the ADL acknowledged that "[t]he mere fact of posting a Pepe meme does not mean that someone is racist or white supremacist... if the meme itself is racist or anti-Semitic in nature, or if it appears in a context containing bigoted or offensive language or symbols, then it may have been used for hateful purposes' (ADL 2016:a).

Thus, the alleged white supremacist undertones of how this manifestation speaks security are still up for debate. This was further complicated by a similar mutation of the Pepe meme posted by former KKK leader David Duke. His manifestation also featured right-wing individuals' faces edited over 'The Deplorables', this time with the tagline, "Anti-racist is a code word for anti-white" (Duke 2016). Thus, what Trump Jr's manifestation clearly did reconstitute was the behaviour of making manifestations and mutations associating Trump with Pepe and the ideal that Pepe was a voice of support for Trump's ideas. What it appears to have reified within certain audiences, both pro and anti-Trump, is the ideal that Trump's security narrative represents white nationalist and anti-Semitic security interests.

\section{Manifestation 4}

The final manifestation this article will examine is a meme taking the form of a comic strip, created and shared by Matt Furie in October 2016 (image 7). The strip shows a sad Pepe morphing into a Trump-Pepe hybrid before turning monstrous and multiplying. Inside the mouth of the monstrous Trump-Pepe forms another sad Pepe. There is then a pane showing an explosion before the cartoon cuts to Pepe screaming in his bed, presumably waking from a nightmare. Shrouded in blue, Pepe hears approaching footsteps, indicated by text reading, "thump, thump, thump." He disappears into his mattress, as if hiding. Furie has titled the manifestation, "To Sleep, Perchance to Meme," which references the Hamlet Soliloquy in which the Shakespearian character considers whether it would be better to die but fears what dreams may come in death. A subtitle states, "The creator of Pepe draws his alt-right election nightmare." Given that, in this rare instance, the sole author of this manifestation is known, this meme can be definitively seen to be speaking security from Furie's own perspective. The textual and visual elements combine to suggest horror and disgust at the purposes for which Furie's character was now being used. 
In 2010, Furie had expressed a bemused happiness at the popularity of the Pepe meme (KYM 2010d). A month before he shared this image, he described feeling little concern and 'amusement' at Alt-Right mutations of his meme. He predicted that, "[co]me November, it's just gonna go on to the next phase [sic]" (Serwer 2016). However, following the ADL classification, Furie re-evaluated his stance. In a statement released at the same time as this manifestation, Furie and his publishers condemned "the illegal and repulsive appropriations of the character by racist fringe groups linked to the alt right...[and] Trump presidential campaign" (Fantagraphics 2016). This meme can be seen to represent Furie's feelings in ways that words alone cannot; employing affect, dark humour and aesthetic elements, including colour, to comment on the life cycle of the Pepe meme to date and express security concerns over a Trump Presidency and return the voice of Pepe back to its 'owner'. Furie then joined the ADL in launching a 'Save Pepe' campaign aimed at re-associating the character with narratives of peace and fun (ADL 2016b). He said, "I understand that it's out of my control, but in the end, Pepe is whatever you say he is, and I, the creator, say that Pepe is love" (Time 2016).

In terms of wider discourse, Furie's manifestation was part of a culture of prominent figures condemning Trump as his win loomed (Boardman 2016). It thus proved to be susceptible to virality so close to the US election, with high longevity and fecundity. It was one manifestation of thousands playing into the discourse of Trump v Hillary, with both potential victories being positioned as a signal of doom. This cartoon strip manifestation was constituted as a form of truth by a number of news sites because it was made by Pepe's original creator, who they deemed to have a certain authority (e.g. Wade 2016). However, this manifestation spoke security in deeply polarising ways. To some, it was an attempt to limit their freedom and stifle Pepe's voice. Many found the manifestation humorous in a different way than it was intended, as they mocked the idea that Pepe belonged solely to Furie or that he could control how Pepe spoke security. For others, this was an attempt to let Pepe speak in the inclusive ways he was originally intended to.

A contestation over Pepe ownership emerged as this manifestation and its intertext encouraged two contrasting sets of behaviours, appropriations and ideals. On one hand, the subsequent Save Pepe movement was part of a growing behavioural trend of creating 'Wholesome Memes' (Feldman 2016). These are "post-ironic, meaning that they convey love, affection and genuine friendship by re-contextualising classic meme formats" (Feldman 2016). For instance, one manifestation of Pepe reading the words 'Supportive Friendships' in a book received over 86000 notes on Tumblr (Feldman 2016). Generally, 'wholesome' Pepe spoke security with the ideal that this character should not represent the Alt-right. However, such manifestations could still speak with layers of irony to certain audiences and be mutated to suit other ends. On this point, there was also a behaviour of continuing to associate Pepe with the Alt-right and an ideal that Furie was not in charge. Due to continued Alt-right manifestations of the meme, Furie decided to kill off the Pepe character in May 2017. He announced the news through a funeral comic strip (KYMa). Once again, some commentators saw this manifestation's speech as highly valid and Pepe's 'death' as a definitive conclusion for the character (e.g. BBC News 2017). However, others continued to create and mutate manifestations, highlighting Furie's lack of power in determining how Pepe speaks security.

The application of the five-point method to the Pepe the Frog case study has thus highlighted how memes metaphorically speak security in complex, ever-changing and powerful ways. Focusing on specific manifestations of the meme, before considering intertext, wider discourse, behaviours, ideals and appropriations, has shown how each manifestation speaks both within its intertextual/ intervisual context as well as independently, through aesthetic, affective and symbolic qualities. Pepe memes have spoken the ideals of the Alt-right, but they have spoken them with ambiguity 
and layers of irony. Their great diversity and polysemy mean that they have not always spoken these ideals and are also capable of challenging them. Today, Pepe remains as polysemic and ambiguous a speaker of security as ever. Furie has relaunched his Save Pepe campaign after it became clear that the character was not dying (Furie \& Furie 2017). Klee contends that "mutability...ensures Pepe will always be bigger and better than the racists who love him" (2016). Pepe will likely always be associated with hate speech in certain contexts, but in others he may speak in desecuritising ways which chime into narratives of peace and reconciliation.

\section{Conclusion}

As cultural units transmitted online, visual internet memes have gained considerable attention in popular discourse in recent years. However, the phenomenon is under-represented in academic, and specifically International Relations, literature. The visual security movement has considered how visuals can metaphorically speak security and securitise particular issues. Theorists of the everyday have focused on how security is not exclusively produced through grand securitising speech acts, but through a greater myriad of seemingly banal acts, or 'little security nothings'. This article has sought to address a silence in security studies by combining these two fields with meme studies to analyse internet memes as visual and everyday speakers of security.

Methodologically, a bricolage approach has drawn from a number of key scholars' visual methods to create a new, broadly sequential method. This has allowed for analysis of memes as not only visual objects/manifestations, but also as behaviours and ideals with wider visuality. It has shown how manifestations metaphorically speak independently of, as well as within, wider discourse, and how they do so with humour, affect and polysemy. It has also highlighted the relevance of meme mutation, distribution patterns, the constitution of truths and displacement of mythical with banal power in memetic security speech.

Applying this method to the case study of Pepe the Frog has highlighted how internet memes can speak security in deeply complex, polysemic and ambiguous ways which echo, and are echoed within, wider political narratives. A single manifestation of Pepe can speak of a white referent object needing to be saved from the non-white 'other' to some, while speaking in an innocuous way to others, and of politically correct liberals as a threat to freedom of speech or satire to yet another audience. Layers of humour can alter and disguise Pepe's security speech, while contestation over ownership and constant mutation and appropriation of the meme make it all the more complex to interpret. Pepe is simultaneously constituted as an irrelevant cartoon, a heroic political character and a hate symbol. However, it is this polysemy and ambiguity that not only allow Pepe to securitise so effectively, but also to potentially de-securitise and counter-securitise. He speaks across international borders and speaks for and to a wide array of political parties, from the US President to anonymous individuals and collectives. Pepe is an active site of the 'little security nothings' of internet culture wars, fought over who security is for and how it should be conducted. His myriad of speech acts have helped to create a security climate in which Trump's most seemingly 'rupturing' grand speech acts securitise.

Internet memes are made, shared and changed at such a quick pace across private, semi-private and public spheres that there is no way of knowing for certain how many are created and mutated worldwide each day, who is responsible for these changes or what their exact motivations are. While this article has provided in-depth analysis of the Pepe meme, it could not feasibly delve into an exploration of all the memetic manifestations, behaviours and ideals of even this one specific case study. It is also limited in so far as it relies on the subjective knowledge of its author. Indeed, the study of memes can never be truly objective, nor should it strive to be. Instead, it should be 
conducted in an intersubjective web of analysis which reflects the polysemic nature of memes. As their significance in many people's everyday lives continues to grow, memes will continue to speak security in louder and more complex ways, contributing more to the myriad of 'little security nothings' which build up debate, consensus and norms surrounding security issues. This study thus calls for more authors to engage with Internet memes as everyday visual speakers of security and suggests some key areas for subsequent research.

Firstly, there should be more scholarship which applies this method, or other tailored methods to empirical examples of internet memes. The more we empirically evaluate memes in all their forms from varied and diverse perspectives, the more our intersubjective knowledge of the complex and polysemic ways they speak security will grow. Pepe is a meme primarily used in the global 'West', but there are many other national and international meme movements in different geographical and cultural contexts to explore (e.g. Mina 2014). Taking the speech of and around memes seriously through feminist, post-colonial and other theoretical lenses will allow for greater insight into the norms and power structures their speech upholds and helps to tear down.

Secondly, the rise of Internet memes has dramatically shifted "who has the ability to see and the talent to speak" in politics (Ranciere 2004: 13). This article has addressed how the opinions of people with limited political power can be expressed through the creation and sharing of Pepe memes. As a result, they have the ability and talent to speak security through Pepe, and to use these 'little amphibian nothings' to build up security narratives. The study of memes as visual (and non/ semi-visual) speakers of security would benefit from more analysis of the nature and consequences of how their speech shifts power from traditional political realms into banal, online settings. It would also benefit from an analysis of who remains silent when internet memes speak. We must ask ourselves which communities are wholly or partially excluded from meme creation, mutation and hegemonic laughter, and how this affects the speech of memes and their wider power dynamics.

Finally, there is an additional layer to the context of Internet memes that this article has not considered but which shapes their speech, consumption and mutation. This relates to the involvement of the online platforms on which memes are shared. Most websites and search engines have sharing rules and limit what can be posted. They also employ algorithms, which are often secretive in nature, to determine who sees shared content and when (Andersen 2017: 359, Aradau \& Blanke 2018). The impact of the power of technology companies on the ways memes speak security should not be underestimated. Thus, further research should continue to assess how web platforms and their algorithms ascertain who or what has the 'talent to speak' (2017: 368).

The speech of internet memes is layered and not easy to understand, nor is it going away. In the time it has taken to write this article, thousands of more memes have likely been created and mutated, each a seemingly banal 'little security nothing' contributing to a wider process of ever-changing security discourse. Whether it be Pepe or other characters who dominate memetic speech in years to come, it is clear that memes are changing how we speak security, and we need to acknowledge their role in the conversation.

\section{About the author}

Loui Marchant graduated from the University of St Andrews with an MA in International Relations in 2018. She is now undertaking an MSc in Gender, Development and Globalisation at the London School of Economics. 


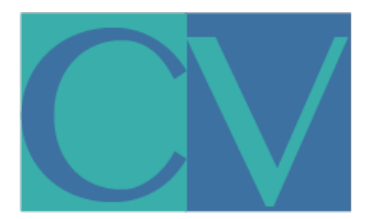

\section{Contemporary}

Bibliography

Image sources ${ }^{[2]}$

Image 1 (2018) Available at https://knowyourmeme.com/photos/945009-feels-good-man (accessed 10/04/2018)

Image 2 (2018) Available at https://knowyourmeme.com/photos/248081-feels-bad-man-sad-frog (accessed 10/04/2018)

Image 3 (2018) Available at https://knowyourmeme.com/photos/862065-smug-frog (accessed 10/04/2018)

Image 4 (2015) 'Super Rare Skinhead Pepe', Pepe \#1 Fan Tumblr, Available at https://premiumpepes. tumblr.com/post/116983043126/super-rare-skinhead-pepe (accessed 10/04/2018)

Image 5 (2015) Available at https://knowyourmeme.com/photos/1004021-smug-frog (accessed $11 / 04 / 2018)$

Image 6 (2016) Donald Trump Jr's Instagram Page, Available at https://www.instagram.com/p/ BKMtdN5Bam5/?hl=en (accessed 11/04/2018)

Image 7 (2016) Matt Furie and The Nib, Available at https://knowyourmeme.com/photos/1181961pepe-the-frog Original image available at https://thenib.com/pepe-the-frog-to-sleep-perchanceto-meme (accessed 11/04/2018)

\section{Academic sources}

Anderson, R, C Mutlu \& J Vuori (2015) 'Visuality', IN Aradau, C, Huysmans, J, Neal, A \& Voelkner, N (eds.), Critical Seucrity Methods: New Frameworks for Analysis: Routledge.

Anderson, R (2017) 'Videos, Algorithms and Security: How digital video platforms produce postsovereign security articulations', Security Dialogue 48(4) 354-372

Aradau, C \& A Hill (2013) 'The Politics of Drawing: Children, Evidence and the Darfur Conflict', International Political Sociology 7(4): 368-387.

Aradau, C \& T Blanke (2018) 'Governing Others: Anomaly and the Algorithmic Subject of Security', European Journal of International Security 3(1) 1-21.

Barthes, R (1977 [1964]) 'Rhetoric of the Image' IN Image, Music, Text Fontana Press.

Barthes, R (2000 [1957]) Mythologies, Vintage Books.

Bleiker, R \& S Butler (2016) 'Radical Dreaming: Indigenous Art and Cultural Diplomacy' International Political Sociology 10(1): 56-74.

Buzan, B, O, Wæver, \& J, de Wilde, (1998) Security: A New Framework for Analysis: Lynne Rienner Publishers.

Buzan, B (2000) 'Change and Insecurity Reconsidered, IN Croft, S \& T Terriff (eds.) Critical Reflections on Security and Change, Frank Cass Publishers 

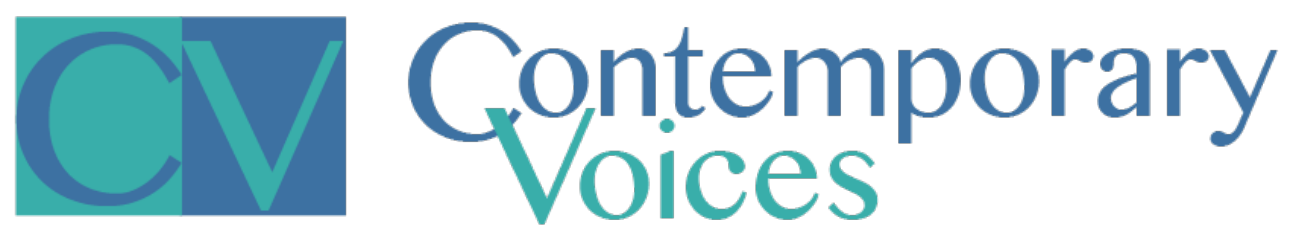

Campbell, E (2011) 'The cultural politics of justice: Bakhtin, Stand-up Comedy and Post-9/11 Securitization', Theoretical Criminology 15(2) 159-177

Croft, Stuart (2006) 'Images and Imaginings of Security', International Relations 20(4): 387-391.

Cloud, D, (2006) 'To Veil the Threat of Terror': Afghan Women and the Clash of Civilisations in the Imagery of the US War on Terror', Quarterly Journal of Speech 90(3): 285-306.

Davidson, P, (2012), 'The Language of Internet Memes', IN Mandiberg, M (ed.) The Social Media Reader. New York University Press.

Davies, M \& M, Niemann (2002) 'The Everyday Spaces of Global Politics: Work, Leisure, Family', New Political Science 24(4): 557-577

Dawkins, R, (1989[1976]) The Selfish Gene: $2^{\text {nd }}$ edition, Oxford University Press.

Der Derain, J, (2005): 'Imaging Terror: Logos, Pathos and Ethos', Third World Quarterly 26(1): 2337.

Enloe, C, (2011) 'The Mundane Matters', International Political Sociology 5(4): 447-450.

Guillaume, X, (2011) 'Resistance and the International: The Challenge of the Everyday.' International Political Sociology Forum Contribution 5(4): 459-462.

Guillaume, X, Anderson, R \& Vuori, J (2016): 'Paint in Black: Colours and the Social Meaning of the Battlefield', European Journal of International Relations 22(1): 49-71.

Hamilton, C (2014) 'What Internet Memes Can Offer International Relations Research' Australian Outlook, Australian Institute of International Affairs, 05/08/14: Available at http://www. internationalaffairs.org.au/australianoutlook/what-internet-memes-can-offer-internationalrelations-research/ (Accessed 07/01/18).

Hansen, L, (2011) 'Theorising the image for Security Studies: Visual securitization and the Muhammad Cartoon Crisis', European Journal of International Relations 17(1) 51-69.

Hansen, L (2012) 'Reconstructing desecuritisation: the normative-political in the Copenhagen School and directions for how to apply it', Review of International Studies 38(3) 525-546

Hansen, L (2015) 'How Images Make World Politics: International Icons and the Case of Abu Ghraib', Review of International Studies 41(2): 263-288.

Heath-Kelly, C \& L Jarvis (2017) 'Affecting Terrorism: Laughter, Lamentation, and Detestation as Drives to Terrorism Knowledge', International Political Sociology 11(3) 239-256.

Heck, A \& G Schlag (2013) 'Securitizing Images: The Female Body and the War in Afghanistan', European Journal of International Relations, 19(4) 891-913

Hristova, S (2014) 'Visual memes as neutralisers of political dissent', TripleC 12(1) 265-275

Huysmans, J, (2011) 'What's in an act? On security speech acts and little security nothings' Security Dialogue 42(4-5): 371-383

Huysmans, J, (2015) 'Democratic Curiosity in Times of Surveillance Blog' European Journal of International Security: Available at https://www.ejis.eu/2015/12/09/democratic-curiosity/ (accessed 14/11/2017) 
Knobel, M \& C Lankshear (2007). 'Online Memes, Affinities, and Cultural Production' IN Knobel, M \& C Lankshear (eds.) A New Literacies Sampler, Peter Lang Publishing INC

Koenigseder, A \& M Leese (2015) 'Humour at the Airport? Visualisation, exposure, and Laughter in the 'War on Terror', International Political Sociology 9(1) 37-52

McDonald, M (2008) 'Securitization and the Construction of Security', European Journal of International Relations 14(4): 563-587.

Methmann, C \& D Rothe (2014) 'Tracing the Spectre That Haunts Europe: The Visual Construction of Climate-Induced Migration in the MENA Region' Critical Studies on Security 2(2) 162-179.

Mina, A X (2014) 'Batman, Pandaman and the Blind Man: A Case Study in Social Change Memes and Internet Censorship in China', Journal of Visual Culture 13(3) 359-375.

Möller, F (2007) 'Photographic Interventions in Post-9/11Security Policy' Security Dialogue 38(2) 179-196.

Nagle, A (2017) Kill All Normies: Online Culture Wars From 4Chan and Tumblr to Trump and the Alt-Right, Zero Books.

Ranciere, J (2004) 'The Politics of Aesthetics', translated, London and New York: Continuum

Ranciere, J (2011) The Emancipated Spectator, Verso

Salter, M (2015) 'No Joking', IN Bajc, V \& de Lint, W (eds.) Security and Everyday Life, Routledge.

Särmä, S (2014) Junk Feminism and Nuclear Wannabes: Collaging Parodies of Iran and North Korea, Academic Article, Tampere.

Särmä, S (2015) 'Collage: An Art-inspired Methodology for Studying Laughter in World Politics', Popular Culture and World Politics: Theories, Methods, Pedagogies, Bristol E-International Relations 110-119.

Shifman, L (2014) Memes in Digital Culture, MIT Press.

Shirky, Clay (2011) 'The Political Power of Social Media: Technology, the Public Sphere and Political Change', Foreign Affairs 28(Jan/Feb): 28-41.

Shirky, C (2012) 'Gin, television and social surplus' IN Mandiberg, M (ed.) The Social Media Reader, New York University Press.

Tickner, A.B, (2005) 'IR Theory as Everyday Practice', paper presented at the Annual International Studies Association Meeting, Honolulu, Hawaii, 2-5 th March http://www.allacademic.com/meta/ p70766 index.html

Vuori, J (2010) 'A Timely Prophet? The Doomsday Clock as a Visualization of Securitization Moves with a Global Referent Object', Security Dialogue 41(3): 255-77.

Vuori, J, (2017) 'Constructivism and Securitisation Studies' IN Balzacq, T \& M Dunn Cavelty (eds.) Routledge Handbook of Security Studies: $2^{\text {nd }}$ edition, Routledge.

Vuori, J \& Saugmann, R (2018) Visual Security Studies: Sights and Spectacles of Insecurity and War: Routledge. 

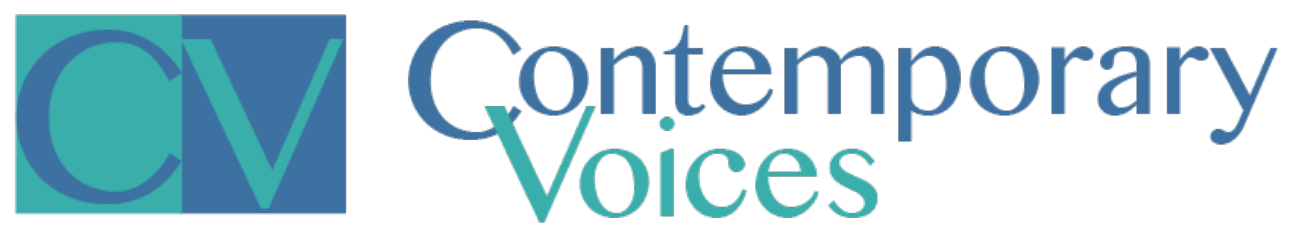

Walt, S (1991) 'The Renaissance of Security Studies', International Studies Quarterly 35(2) 211-39.

Warrington, A, (2017) 'Countering Violent Extremism via de-securitisation on Twitter', Journal of Deradicalisation 11: 258-273.

Weldes, J \& C Rowley (2012) 'The Evolution of International Security Studies and the Everyday: Suggestions from Buffyverse', Security Dialogue 43(6): 513-530.

Williams, M (2003) 'Words, Images and Enemies: Securitization and International Politics', International Studies Quarterly 47 (4): 511-531.

\section{Journalistic online sources}

BBC News (2017) 'Pepe the Frog 'is killed off to avoid being a hate symbol', 08/05/2017: Available at: http://www.bbc.co.uk/news/world-us-canada-39843468 (accessed 28/03/2018)

Bennett, J (2016) 'Here's How Two Twitter Pranksters Convinced The World That Pepe The Frog Is Just A Front For White Nationalism', The Daily Caller, 14/09/2016: Available at http://dailycaller. com/2016/09/14/heres-how-two-twitter-pranksters-convinced-the-world-that-pepe-the-frogmeme-is-just-a-front-for-white-nationalism/ (accessed 15/02/2018)

Boardman, M (2016) 'Stars Who Spoke Out Against Donald Trump', Entertainment Weekly, 04/10/2016: Available at http://ew.com/gallery/stars-against-trump/ (accessed 11/04/2018)

Di Placido, D (2017) 'How 'Pepe The Frog' Became a Symbol of Hatred' Forbes, 09/05/2017: Available at https://www.forbes.com/sites/danidiplacido/2017/05/09/how-pepe-the-frog-becamea-symbol-of-hatred/\#715e1eb0426b (accessed 29/03/2018)

Fantagraphics (2016) 'The Truth About Pepe the Frog' 6/10/2016: Available at http://fantagraphics. com/flog/truthaboutpepe/ (accessed 09/04/2018)

Feldman, B (2016) 'The Next Frontier in Internet Culture is Wholesome Memes About Loving Your Friends', New York Magazine, 10/08/2016: Available at http://nymag.com/selectall/2016/08/thenext-frontier-in-internet-culture-is-wholesome-memes.html

Furie, M (2016) 'Pepe the Frog's Creator: I'm Reclaiming Him. He Was Never About Hate', Time, 13/10/2016: Available at http://time.com/4530128/pepe-the-frog-creator-hate-symbol/ (accessed 19/03/2018)

Harrington, J (2014) 'Dear America, I Saw You Naked-And Yes, We Were Laughing. Confessions of an ex-TSA Agent', Politico Magazine, 30/01/2014: Available at https://www.politico.com/magazine/ story/2014/01/tsa-screener-confession-102912 (Accessed 05/01/18).

Harrington, R (2016) 'Here's what Trump means when he says 'drain the swamp' - even though it's not an accurate metaphor', Business Insider UK, 11/11/2016: Available at http://uk.businessinsider. com/what-does-drain-the-swamp-mean-was-dc-built-on-a-swamp-2016-11?r=US\&IR=T

Jacobs, B (2016) 'Hillary Clinton regrets 'basket of deplorables' remark as Trump attacks', The Guardian, 13/09/2016: Available at https://www.theguardian.com/us-news/2016/sep/10/hillaryclinton-basket-of-deplorables-donald-trump (accessed 22/03/2018) 

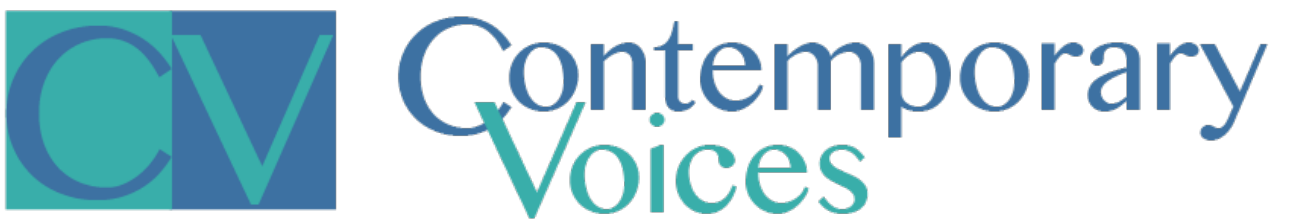

Jacobs, B, D Roberts \& S Siddiqui (2016) 'Donald Trump threatens to jail Hillary Clinton in second presidential debate', The Guardian, 10/10/2016: Available at https://www.theguardian.com/usnews/2016/oct/10/debate-donald-trump-threatens-to-jail-hillary-clinton (accessed 22/03/2018)

Kircher, M (2016) 'How the Anti-Defamation League Decided Pepe the Frog was a Symbol of AntiSemitism', New York Magazine, 30/09/2018: Available at http://nymag.com/selectall/2016/09/adlclassifies-pepe-the-frog-as-hate-symbol.html (accessed 18/02/2018)

Klee, M (2016) 'Pepe the Frog is not a Nazi, no matter what the alt-right says', The Daily Dot, 12/09/2016: Available at https://www.dailydot.com/unclick/pepe-the-frog-alt-right-whitesupremacist/ (accessed 15/02/2018)

NBC News (2016) 'Clinton Asks Voters To Imagine Trump With 'The Nuclear Codes', 04/09/2016: Available at https://www.nbcnews.com/video/clinton-asks-voters-to-imagine-trump-with-thenuclear-codes-801173059905

Nuzzi, O (2016) 'How Pepe the Frog Became a Nazi Trump Supporter and Alt-Right Symbol', The Daily Beast, 26/05/2016: Available at https://www.thedailybeast.com/how-pepe-the-frog-becamea-nazi-trump-supporter-and-alt-right-symbol (accessed 12/01/2018).

Owen, P (2016) 'David Duke, Roger Stone Turn Clinton's 'Deplorables' Comment Into 'Expendables' Memes (Photos)', The Wrap, 11/09/2016: Available at: https://www.thewrap.com/david-dukeroger-stone-turn-clintons-deplorables-comment-into-expendables-memes-photos/ (accessed 20/03/2018)

Reilly, K (2016) 'Here Are All The Times Donald Trump Insulted Mexico', Time, 31/08/2016: Available at http://time.com/4473972/donald-trump-mexico-meeting-insult/ (accessed 20/03/2018)

Revesz, R (2016) 'Hillary Clinton Attacks Donald Trump for Posting Pepe the Frog Meme', The Independent, 13/09/2016: Available at http://www.independent.co.uk/news/world/americas/ donald-trump-hillary-clinton-pepe-frog-instagram-breitbart-white-supremacist-alex-jonesmilo-a7240581.html (accessed 16/11/2017).

Serwer, A (2016) 'It's Not Easy Being Meme', The Atlantic, 13/09/2016: Available at https:// www.theatlantic.com/politics/archive/2016/09/its-not-easy-being-green/499892/ (accessed 17/11/2017).

Solon, O, (2013) 'Richard Dawkins on the Internet's Hijacking of the Word 'Meme', Wired, 20/06/2013: Available at http://www.wired.co.uk/article/richard-dawkins-memes (accessed 16/11/2017).

Wade, C (2016) 'Pepe the Frog Creator Matt Furie Pens New Comic Showing Pepe's Alt-Right Nightmare', Paste Magazine, 17/10/2016: Available at https://www.pastemagazine.com/ articles/2016/10/pepe-the-frog-creator-comic-alt-right-nightmare.html (accessed 22/03/2018)

\section{Other online sources}

Anti-Defamation League (2016a) 'General Hate Symbols: Pepe the Frog': Available at https://www. adl.org/education/references/hate-symbols/pepe-the-frog (accessed 15/11/2017)

Anti-Defamation League (2016b) 'ADL Joins With 'Pepe' Creator Matt Furie in Social Media Campaign to \#SavePepe', 14/10/2016: Available at https://www.adl.org/news/press-releases/adljoins-with-pepe-creator-matt-furie-in-social-media-campaign-to-savepepe (accessed 15/11/2017) 
Anti-Defamation League ${ }^{[3]}$ (c) 'Valknot': Available at: https://www.adl.org/education/references/ hate-symbols/valknot (accessed 09/04/2018)

Anti-Defamation League (d) 'Celtic Cross': Available at: https://www.adl.org/education/references/ hate-symbols/celtic-cross (accessed 09/04/2018)

California Welfare and Institutions Code (WIC) Division 5 Part 1 Section 2, California Legislative Information, Available at http://leginfo.legislature.ca.gov/faces/codes displaySection. xhtml? sectionNum=5150\&lawCode=WIC (accessed 25/01/2018)

Furie, M \& J Furie (2017) 'Save Pepe' Kickstarter Campaign: Available at https://www.kickstarter. com/projects/615106574/save-pepe (accessed 20/03/2018)

IMDb (2010) 'The Expendables': Available at http://www.imdb.com/title/tt1320253/ (accessed 03/04/18)

Know Your Meme (a) 'Pepe the Frog': Available at http://knowyourmeme.com/memes/pepe-thefrog (accessed 18/02/2018)

Know Your Meme (b) '/b/': Available at http://knowyourmeme.com/memes/sites/b (accessed 18/02/2018)

Know Your Meme (c) 'Wojak/Feels Guy': Available at http://knowyourmeme.com/memes/wojakfeels-guy (accessed 12/03/18)

Know Your Meme (d) 'O\&A with Matt Furie': Available at http://knowyourmeme.com/blog/ interviews/qa-with-matt-furie (accessed 10/04/2018)

Know Your Meme (e) 'Nazi Pepe Controversy Images': Available at https://knowyourmeme.com/ memes/events/nazi-pepe-controversy/photos (accessed 31/07/2018)

Wordpress (2018) Available at https://saboteur365.wordpress.com/tag/mexican-border/ (accessed 19/04/2018)

\section{Social media pages}

Duke, D (2016) 10/09/2016, Available at https://twitter.com/drdavidduke/ status/774804699644125184 (accessed on 19/04/2018)

Kualify (2018) Tumblr Page: Available at http://kualify.tumblr.com/ (accessed 05/03/2018)

Premium Pepes (2018) Pepe \#1 Fan Tumb/r Page: Available at https://premiumpepes.tumblr.com/ post/116983043126/super-rare-skinhead-pepe (accessed 06/03/2018)

Trump, D (2015), Twitter Page, 13/10/2015: Available at https://twitter.com/realdonaldtrump/ status/653856168402681856?lang=en (accessed 10/04/2018)

Trump, D (2016) Twitter Page, 2/06/2016: Available at https://twitter.com/realdonaldtrump/ status/749261175968436224?lang=en (accessed 10/04/2018)

Trump Jr, D (2016) Instagram Page, 11/09/2016: Available at https://www.instagram.com/p/ BKMtdN5Bam5/?hl=en (accessed 11/04/2018)

[3] There was no publication date for this web page. The same rule applies for all of the web pages listed with no date. However, I have provided the access dates. 